\title{
Study on the Sustainable Development of Logistics for Circulation Economy
}

\author{
Zhao Rong \\ School of Economic and Management \\ Shengyang Aerospace University \\ Shengyang China
}

\begin{abstract}
-since the nineteen seventies, resource and environmental problems have become one of the important problems in the world, it is mainly because of human use of resources and the environment is incorrect and the development of human society and the natural harmony does not cause. Extensive economic growth mode has caused profound reflection of human, the traditional mode of development gave birth to the environmental problems in the trigger a crisis of resources at the same time. Thus the concept of circular economy, circular economy is the industrialization since the high consumption and high pollution, extensive mode of economic form, is a kind of feedback circulation economy mode of human use in order to achieve sustainable development. The core of circular economy is the efficient use and recycling of resources, it takes "reduce, reuse, recycle" principle, in order to promote the benign cycle of human society and the natural system as the goal.This paper starts from the recycling economy and sustainable development of logistics theory, points out the bottleneck of sustainable development of logistics, analyzes the deep relationship between the development of green logistics and Sustainable Logistics reverse logistics, the circular economy, discusses the mutual influence between them, discusses the implementation of Sustainable Logistics can improve the environment, and promote sustainable development. Finally this paper analyzes current situation of Sustainable Logistics in developed countries, summarizes the existing problems in the sustainable development of logistics.
\end{abstract}

Keywords-Circular economy ; Green logistics ; Reverse logistics; Sustainable logistics

\section{INTRODUCTION}

In recent years, with the construction and development of market economy, developing modern logistics has been seen as the main direction all over the country. However, people only pay attention to economic effect during this boom without attaching importance to the outer negative effect within each section of logistics. With the development and improvement of world economy, daily logistics has brought many environmental problems, such as increase of noise, release of hazardous gas, large area of traffic congestion, unnecessary consumer of resources, increase of waste and so on, all of which are inconsistent with new sustainable principle of economic development. However, this provides the basis for exploring development strategies of sustainable logistics under the circumstance of circular economy. First the paper analyzes the developmental theories of circular economy and sustainable logistics and then it studies the operating mechanism of modern sustainable logistics. Development countermeasures of modern sustainable logistics in our country are discussed in the paper with taking logistics, economy, resources and environment into consideration comprehensively.

In conclusion, modern sustainable logistics plays an important role in economic society. However, as the development of logistics in our country started late, it still in the initial stage, so unavoidably it will have some conflicts with modern sustainable logistics. Therefore, to realize sustainable logistics in our country, we should transfer the existing development mode of economy and build new circular logistics system. By doing this, we can use resources effectively and reasonably. Meanwhile, we should give full play to the common efforts of businesses and government so that sustainable logistics can be realizes gradually.

\section{BRIEF INTRODUCTION TO THE CIRCULAR ECONOMY}

\section{A. Content and Feature of Circular Economy}

Circular economy, short for Material Closed-loop Mobile Economy, is characterized by usage of material, energy cascade and closed-loop. It transferred the traditional linear growing economic model relying on resources consumption to the new economy model relying on ecological circulation of resources in the big system of humans, resources, science and technology, as well as in the whole process of resources investment, cooperation's production, product consumption and abandon.

\section{B. Principles of Developing Circular Economy}

$3 \mathrm{R}$ are the three acting principles of circular economy, which are short for reduce, reuse and recycle. Each of the three is indispensable to the effective implementation of circular economy. Method in the input end-reduce, aims to minimize the material used for production and consumption; method in the process - reuse, aims to lengthen the time of service and product effectively; principle of recycle belongs to the method of output end.

\section{1) Reduc}

Reduce, as the first principle of circular economy, aims to minimize the material used for production and consumption.

2) Reuse 
Reuse, the second principle of circular economy, aims to extend validity of products. That is to say, products can be used repeatedly. The period of product turning into waste can be extended by reuse.

3) recycle

Recycle, the third principle of circular economy, means that to reduce the final waste by turning waste into resources again. In other words, to realize recycle of resources as possible as we can.

\section{DEVELOPMENT OF SUSTAINABLE LOGISTICS}

\section{A. Content of Sustainable logistics}

Based on the 3R principles, sustainable logistics takes the maximization of economy, society and environment as its fundamental target. Advanced technology is used in the package and storage with putting environment protection as the premise. Realizing the flow of natural material resources from suppliers to receivers and afterwards a reverse flow between them, thus a systematic process of entity flow can be formed.

Its connotation includes three aspects. intensive resources; adopting methods and technology of green transportation, green storage and green package; and reverse logistics.

Sustainable logistics contains green logistics and reverse logistics. It promotes material cycle by restraining waste. The consumption of natural resources will be reduced and environment will be improved. Economic development will be in a continuous condition under a society with little environmental destruction.

\section{B. Green Logistics in the Sustainable Logistics}

1) Green logistics can promote the development of sustainable logistics

Green logistics is the core of circular economy as well as the major component of sustainable logistics. Green logistics means that it won't harm the environment during the process but purify the logistics environment instead, which can make the best use of logistics resources.

2) The realistic significance of developing green logistics in the sustainable logistics

Green logistics has realized both economic and ecological effect, promoting the common development of the two. Green logistics is a major part of the sustainable development of logistics. While bringing great economic and social benefit to humans, logistics also brought huge challenges to environment and resources. There's a necessary link between the ineffective logistics business and the excessive release of carbon dioxide. They are all aggravating noise pollution and light pollution. Meanwhile, the ineffective load program and traffic congestion in the city lead to a bad logistics service. Hence, to develop green logistics and change the traditional logistics is of high priority in the development of sustainable logistics.

\section{Reverse logistics in the sustainable logistics}

The basis of sustainable logistics is the reverse logistics. Human activities is a major part of ecosystem. Sustainable logistics makes the waste back to the production process again by recycling and disposing wastes and reusing renewable resources. Through reverse logistics, some defective products, waste materials and wastes during production can be turned into renewable products again by recovery process. While some wastes of no using values can be back to the ecosystem again after strict processing to realize the recycle and reuse of resources so that to improve the utilization of resources effectively and reduce the burden of ecological environment.

Sustainable logistics and reverse logistics are supplement of each other with mutual promotion. The cycle process of sustainable logistics is "resourcesproducts-waste-renewable resources". This process can reduce emissions of pollutants. We can achieve best economic and social benefit with minimum invests by making best use of this cycle process in economy circulation.

Reverse logistics can promote the development of sustainable logistics

Sustainable logistics, a brand new idea of social development, emphasizing coordinated development among economy, society and environment, has been valued by various countries consistently. Reverse logistics is one of the major means in realizing sustainable development of logistics.

\section{ANALYSIS OF SYSTEM AND STRUCTURE OF SUSTAINABLE LOGISTICS}

\section{A. Structure of Sustainable logistics}

Developing sustainable logistics is an important measure in saving resources and protecting environment as well as implementing scientific development view. To develop circular economy, it's necessary to develop sustainable logistics. Adhering to ecological rules and economic laws, sustainable logistics aims to reduce and recycle wastes and make them harmless. Sustainable logistics combines cleaner production, comprehensive utilization of resources, ecological design, consumption and other logistics process all together to make the economic system cycle with natural ecosystem harmoniously, which can maintain balance of natural ecology and promote sustainable development of society.

Sustainable logistics can be divided into two kinds, obverse logistics and reverse logistics. Obverse logistics is the main channel of logistics which meets consumers' needs with the process of production, transportation and consumption; while reverse logistics has the opposite process compared with the obverse logistics. It disposes the derivations during the logistics appropriately, such as recycling, sorting, purification, refinement, waste disposing and so on.

\section{1) Operation of Sustainable Logistics}

It's beneficial to restrain the bad effect of logistics on the environment to develop sustainable logistics scientifically and reasonably and change the traditional relationship of one-way function among economic development, logistics, production and consumption. Meanwhile, it also helps to form a circular logistics system which can promote harmony and healthy development of economy and consumption. This requires each part of the supply chain should be changed 
in the logistics operation. Intensifying the management of reverse logistics while developing obverse logistics so that to reduce resources consumption and reduce the bad effect on natural environment, forming a sound circulation of development and environment protection. Sustainable logistics can extend business of the thirdparty logistics providers, so new evaluation index should be adopted during logistics outsourcing to realize management of closed-loop supply chain. Structure of sustainable logistics under sustainable logistics model is shown in FIG.1.

2) Building Systematic Structure of Sustainable Logistics

Sustainable logistics aims to reduce pollution from logistics and reduce consumption and waste of resources. It employs advanced technology to plan and implement its circular activities such as package, storge, transportation, load, processing and recycling.

The precondition to build a sustainable logistics system is that society, government, and cooperations should set up awareness of environmental protection and energy saving. Meanwhile, related policies, laws and regulations which are beneficial for developing sustainable logistics should be established and perfected.

To sum up, to realize sustainable logistics under circular economy, we should combine obverse logistics with reverse logistics and build a logistics system which can optimize economic effect and environment effect together. In the end, resources from the natural environment to the social economic system can be minimized; meanwhile various kinds of wastes from the social economic system to the natural environment can be minimized as well. It's beneficial for environment protection and promotion of sustainable economic development to perfect logistics operation and realizes overall optimization and minimum harm to environment.

\section{SUGGESTIONS TO THE DEVELOPMENT OF SUSTAINABLE LOGISTICS IN OUR COUNTRY}

Developing sustainable logistics and building resource-saving society is a systematic project of great significance concerning various fields of social economy. Developing sustainable logistics is an important measure to develop circular economy and improve resources recycling rate. To develop sustainable logistics, attention should be paid to several aspects as follows,

1) It is of great significance to have a good knowledge of sustainable logistics since it is an important way to realize recycling of resources.

Sustainable logistics combines cleaner production, ecological design, comprehensive utilization of resources and sustainable consumption all together to reduce the waste, to change waste into resources and to make waste harmless. Sustainable logistics, as an important aspect of circular economy, is of great significance to develop healthy and comprehensive circular economy.

2) Encouraging various models to develop sustainable logistics

From the perspective of operational forms, logistics can be generally divided into three kinds, they are production logistics, enterprise self-support logistics and third-party logistics outsourcing. At present the logistics is developing from the former two to the third. However, promotion and development of sustainable logistics in our country is very unbalance, most enterprises and regions are still in a state of low level and small scale. Bases and conditions are not mature enough to enforce sustainable logistics thoroughly.

3) To set up a logistics platform between enterprises and industries, regions and society. To build a sound mechanism for communication among enterprises and various elements.

The 3R principles should be employed to build a integrative system of sustainable logistics if we want to implement material closed-loop flow among enterprises, regions and society. Enterprise, as an element of society, its main functions are transforming resources, manufacturing products and generating wastes. So to manage sustainable logistics, we should start from enterprises. First logistics platform among enterprises and other elements should be set up to realize the vertical and lateral collaboration of resources in the industrial chains. Meanwhile, sound mechanism need to be built to make the best of resources recycling in a short time at the top speed.

I think reasonable construction of ecological industrial park in different regions should be encouraged. Also a double-track recovery system within the whole society should be built. Waste from the upstream enterprise can be transformed into raw material and energy for the downstream enterprise in this system. Thus food chain within ecological industrial park will be formed and a wide range of network system of the whole society will be finally established. Recycling of waste will then become faster and more efficient.

4) To build a network about information of waste covering the whole country, which is adapted to the development of modern sustainable logistics.

Since development of sustainable logistics in our country has a short history, so market network in the whole society needs to be further established and perfected. At present, information transfer in all aspects is not smooth and market regulation is blind as well. Therefore the main factor that restrains developing sustainable logistics is lacking accurate, comprehensive, and convenient information network system for sustainable logistics market. Hence we should attach great importance to this restrictive factor if we want to develop sustainable logistics. In terms of the current information system, the two main problems concerning waste flow are poor centralization of information and information of low quality. Without a nationwide centralized, integrated and efficient information network system for waste flow, they can only be released and disposed casually under market spontaneity.

In my opinion, to build a network system for sustainable logistics, we should put great efforts to build a information network system adapted to the waste flow with constructing conservation-minded society as the overall situation and combining the current situation of sustainable logistics in our country. To build a network platform for waste flow by integrating and optimizing the existing network resources. By centralizing and unifying information resources all over the country, we 
can have a comprehensive and scientific collection, analysis, processing and disposing of waste flow information in time, so that we can build a nationwide information network for sustainable logistics.

\section{CONCLUSION}

Based on circular economy, sustainable logistics make the limited natural material resources recycle reasonable and durable in the cycle process "resourceproducts-wastes-renewable resources". Conflict between economic development and environment protection will be resolved fundamentally by relieving pressure that economic growth on resources.

Process of sustainable logistics is a closed system which contains not only environment protection and green logistics respecting natural ecology but also includes the reverse logistics characterized by recovery, reuse and recycle of resources. It aims to realize sustainable development by recycling resources for many times and improving utilizing rate of resources effectively, as well as relieving the destruction to ecological environment. To reach this goal, it needs support from both green logistics and reverse logistics.
Only if we have a smooth sustainable logistics, then a closed cycle process can be formed. Materials and resources can be recycled effectively at a low cost to realize development of sustainable logistics under circular economy.

\section{REFERENCES}

[1] Liu Jianwei, Yu Haixia.Construction of Modern Logistics Based on the development of Sustainable Logistics[J].Research on Productivity,2007

[2] Bao Jufang,Yin Yarong,Xufang, etc.Research on Logistics Based on Sustainable Logistics [J].Commercial Times, 2007.

[3] Jiahu,Xu Huichao.Environmental Resources and Sustainable Logistics [J].Modern Management Science, 2007.

[4] Wu Xiani.Analysis of Reverse Logistics and Sustainable Logistics [J].Science\&Technology Information,2010,(26).

[5] Yangzhi,Xuling.Reverse Logistics:Inevitable Choice of Sustainable Logistics [J].China's Circulation Economy,2008,(12).

[6] Jean- Paul Rodrigue , Brian Slack, Claude Comtois1TheHandbook of Logistics and Supply ChainManagement1London: Pergamon/Elsevier, 2001

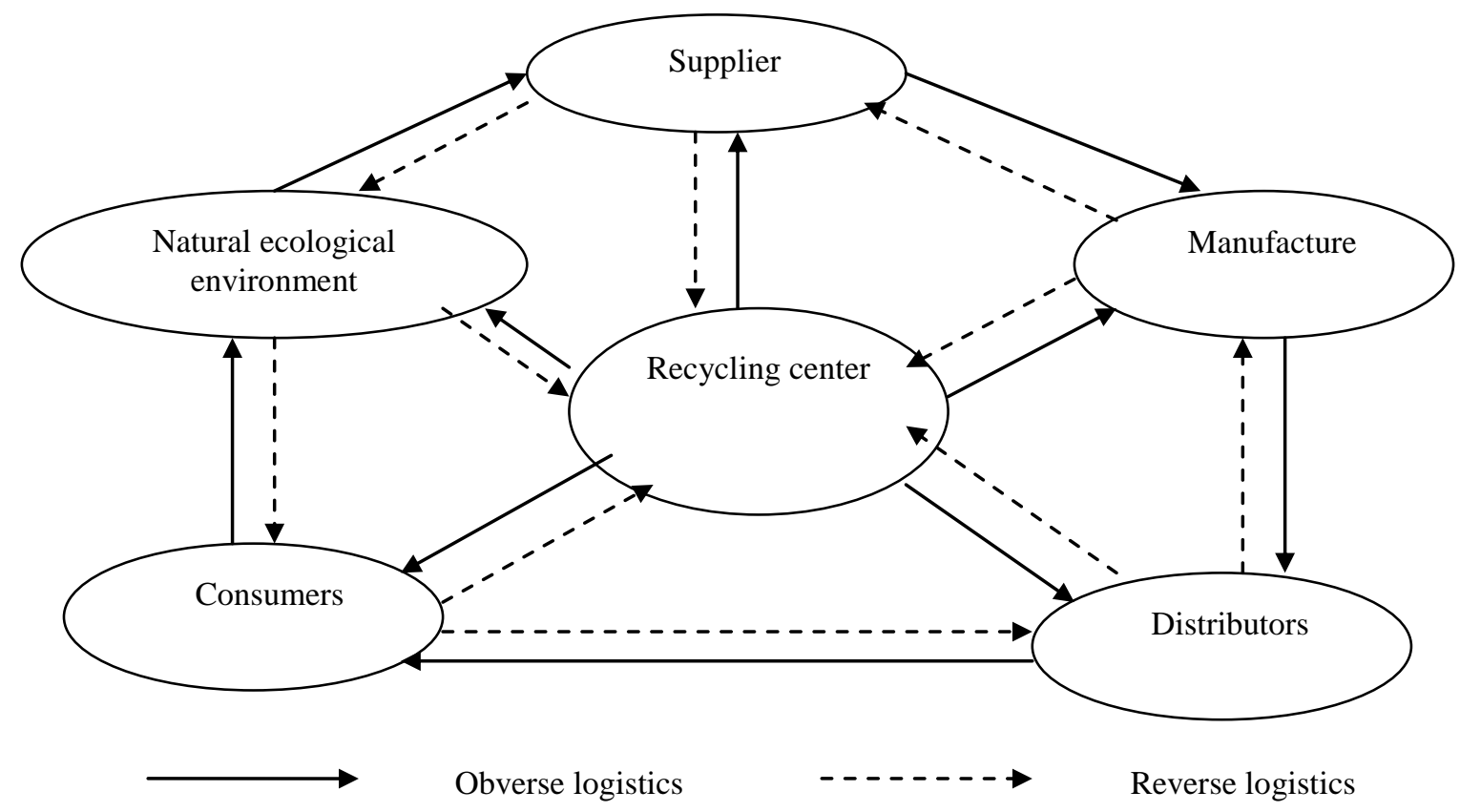

Figure 1. system model of sustainable logistics 